\title{
Can the economic crisis have an impact on tuberculosis in the EU/EEA?
}

M J van der Werf (Marieke.vanderWerf@ecdc.europa.eu) ${ }^{1}$, J Giesecke ${ }^{1}$, M Sprenger $^{1}$

1. European Centre for Disease Prevention and Control (ECDC), Stockholm, Sweden

Each year, 24 March marks World Tuberculosis Day in an attempt to raise public awareness about the epidemic. The European Parliament Committee on the Environment, Public Health and Food Safety will exchange their views on tuberculosis (TB) in Europe in a debate on 21 March 2012. In preparation of this debate concerns were raised about the effect of the current economic crisis on TB.

Many countries in the European Union (EU) and the European Economic Area (EEA) are in an economic recession. It is acknowledged that a recession or economic crisis can have an effect on the population's health, especially with respect to infectious diseases [1]. There are two main mechanisms through which an economic crisis can have an effect on infectious diseases. Firstly, if due to a decrease in country and individual income, less money is spent on healthcare and social welfare. And secondly, if due to an increase in poverty and stress, the number of people belonging to risk groups for infectious diseases increases.

There is evidence that budgets for healthcare are cut in times of economic hardship [2]. Experts from EU/EEA countries predict that there will be an impact of the current global crisis on the financial and human resources available for the control of communicable diseases [3]. Decreased spending on healthcare may result in a reduction of healthcare workers and even of the number and quality of available healthcare facilities, which will have an impact on access to healthcare. Low access to healthcare is associated with longer delays in the diagnosis of TB [4]. This would increase the pool of individuals with infectious TB, as would treatment that is delayed or of insufficient quality.

A financial crisis can increase the size of groups with a high risk for TB. For example, it is generally believed that rising unemployment favours criminal behaviour, and that this leads to a larger prison population [5]. On a population level it has been shown that the size of the prison population is associated with TB incidence [6]. Also, unemployment and job insecurity appear to lead to behaviour that increases the risk for TB, e.g. increased alcohol consumption [7,8]. A study of the impact of the New York City's fiscal crisis in 1975 found that the number of homeless people increased by $300 \%$ [9]. Homeless people are a well known risk group for TB $[10,11]$.

Thus there is evidence that an economic crisis can impact on access to care and quality of care and on the number of individuals that are exposed to risk factors for TB. However, is there evidence that an economic crisis can influence tuberculosis incidence or mortality? A recently published systematic review assessing the impact of economic crises on communicable disease transmission and control included eight studies that report the effect of a crisis on TB [1]. Seven of the eight studies were conducted in non-EU countries and showed that a crisis indeed led to increased incidence, prevalence or mortality of TB. The eighth study, conducted in EU countries, did not show any significant effects. In that study, data for social protections, i.e. availability of social welfare programmes, and for job insecurity was missing for many countries, which makes the detection of immediate changes in mortality difficult. All eight studies were conducted before the current economic crisis started and do therefore not provide direct information about the effect of the current situation on tuberculosis.

On 19 March 2012, the European Centre for Disease Prevention and Control (ECDC) and the World Health Organization Regional Office for Europe published the report Tuberculosis Surveillance and Monitoring in Europe 2012 [12]. The report will for the first time present monitoring indicators that assess the implementation of the Framework Action Plan [13,14]. A rapid communication published in this issue of Eurosurveillance presents an overview of these indicators [15]. One indicator is the trend in the TB case notification rate. Over the last five reporting years, the EU/EEA has experienced a sustained annual decline of $4.4 \%$ in TB notification rates, from 17.5 per 100,000 population in 2006 to 14.6 in 2010 [12]. Thus, the European data do not at this moment show an effect of the current economic crisis on TB. Since TB is a slow disease with a minimum 
incubation period of eight weeks it may take time to see a significant increase in the number of cases. It is even possible that we will initially see a further decrease in the number of TB cases because the healthcare system may experience difficulties in diagnosing and notifying TB. However, it has been shown that in Europe, TB notifications are higher where national incomes are lower and/or income inequalities are higher [16]. If the current financial crisis affects these two variables, then TB rates may well rise.

National experts of EU/EEA countries who participated in a scoping study that assessed the effects of the current global crisis on communicable diseases expect that there will be budget cuts especially in prevention services and in services targeted at vulnerable and hard-to-reach population groups [3]. In Romania, the expiration of a grant from the Global Fund for AIDS, tuberculosis and malaria in June 2010 resulted in reduced provision of prevention services for intravenous drug users. This was followed by a rise in the combined use of opioids and amphetamine-type stimulants resulting in increased injecting frequency. It is likely that this has contributed to increased HIV transmission [17]. As a result of a financial crisis, the Department of Health of the City of New York cut the budget by $20 \%$ between 1974 and 1977 and lost 1,700 staff members; seven of 20 district health centres and six of 14 chest clinics were closed [2]. TB rates began to rise, and New York City experienced a subepidemic of multidrug-resistant TB (MDR-TB). A cost-of-illness study assessing the excess medical expenditures showed that about 10,000 excess TB cases (of a total of 47,000) occurred between 1979 and 1999 [2]. The excess medical expenditures were estimated at USD 0.5 billion. Thus, countries cutting budgets for TB control can expect challenges in controlling TB and increased costs for controlling TB in the future.

Given the likely influence of an economic crisis on the functioning of healthcare systems and on factors that affect the epidemiology of TB, it is expected that the current economic crisis will have an effect on the TB situation in EU/EEA countries. This will be especially true in countries that were already experiencing problems with TB control before [18]. Also, control of MDR- and extensively drug-resistant (XDR-)TB requires a well-established and functioning healthcare system that is able to diagnose cases and provide them with expensive treatment and long-term care. In the light of the predicted budget cuts, ECDC will monitor the effect of the economic crisis on TB in EU/EEA countries by collecting and analysing the TB notification data, and advocate to sustain or even enlarge the budget for TB control.
2. Freudenberg N, Fahs M, Galea S, Greenberg A. The impact of New York City's 1975 fiscal crisis on the tuberculosis, HIV, and homicide syndemic. Am J Public Health. 2006;96(3):424-34.

3. Rechel B, Suhrcke M, Tsolova S, Suk JE, Desai M, McKee M, et al. Economic crisis and communicable disease control in Europe: a scoping study among national experts. Health Policy. 2011;103(2-3):168-75.

4. Storla DG, Yimer S, Bjune GA. A systematic review of delay in the diagnosis and treatment of tuberculosis. BMC Public Health. 2008;8:15.

5. Box S, Hale C. Unemployment, imprisonment and prison overcrowding. Contemporary Crisis. 1985;9(3)209-28.

6. Stuckler D, Basu S, McKee M, King L. Mass incarceration can explain population increases in TB and multidrug-resistant TB in European and central Asian countries. Proc Natl Acad Sci U S A. 2008;105(36):13280-5. I

7. Catalano R, Goldman-Mellor S, Saxton K, Margerison-Zilko C, Subbaraman M, LeWinn K, et al. The health effects of economic decline. Annu Rev Public Health. 2011;32:431-50.

8. Rehm J, Samokhvalov AV, Neuman MG, Room R, Parry C, et al. The association between alcohol use, alcohol use disorders and tuberculosis (TB). A systematic review. BMC Public Health. 2009;9:450.

9. Paolo WF Jr, Nosanchuk JD. Tuberculosis in New York city: recent lessons and a look ahead. Lancet Infect Dis. 2004;4(5):287-93.

10. Love J, Sonnenberg P, Glynn JR, Gibson A, Gopaul K, Fang Z, et al. Molecular epidemiology of tuberculosis in England, 1998. Int J Tuberc Lung Dis. 2009;13(2):201-7.

11. Romaszko J, Buciński A, Wasiński R, Rosłan A, Bednarski K. Incidence and risk factors for pulmonary tuberculosis among the poor in the northern region of Poland. Int J Tuberc Lung Dis. 2008;12(4):430-5.

12. European Centre for Disease Prevention and Control (ECDC)/ WHO Regional Office for Europe. Tuberculosis surveillance and monitoring in Europe 2012. Stockholm: ECDC; Mar 2012. Available from: http://www.ecdc.europa.eu/en/publications/ Publications/1203-Annual-TB-Report.pdf

13. European Centre for Disease Prevention and Control (ECDC). Progressing towards TB elimination. Stockholm: ECDC; 2010. Available from: http://www.ecdc.europa.eu/en/publications/ Publications/101111_SPR_Progressing_towards_TB_ elimination.pdf

14. European Centre for Disease Prevention and Control (ECDC). Framework action plan to fight tuberculosis in the European Union. Stockholm: ECDC; Feb 2008. Available from: http:// www.ecdc.europa.eu/en/publications/Publications/0803 SPR_TB_Action_plan.pdf

15. Sandgren A, Hollo V, Huitric E, Ködmön C. Epidemiology of tuberculosis in the EU/EEA in 2010 - monitoring the progress towards tuberculosis elimination. Euro Surveill. 2012;17(12): pii=20124. Available from: http://www. eurosurveillance.org/ViewArticle.aspx?Articleld=20124

16. Suk JE, Manissero D, Büscher G, Semenza JC. Wealth inequality and tuberculosis elimination in Europe. Emerg Infect Dis. 2009;15(11):1812-4.

17. Pharris A, Wiessing L, Sfetcu O, Hedrich D, Botescu A, Fotiou $A$, et al. Human immunodeficiency virus in injecting drug users in Europe following a reported increase of cases in Greece and Romania, 2011. Euro Surveill. 2011:16(48):pii=20032. Available from: http://www.eurosurveillance.org/ViewArticle. aspx?Articleld $=20032$

18. Ibraim E, Stoicescu IP, Homorodean D, Popa C, Burecu M, Stoicescu I, et al. [Tuberculosis in Romania. Problems and solutions]. Pneumologia. 2010;59(1):6-12. Romanian. 